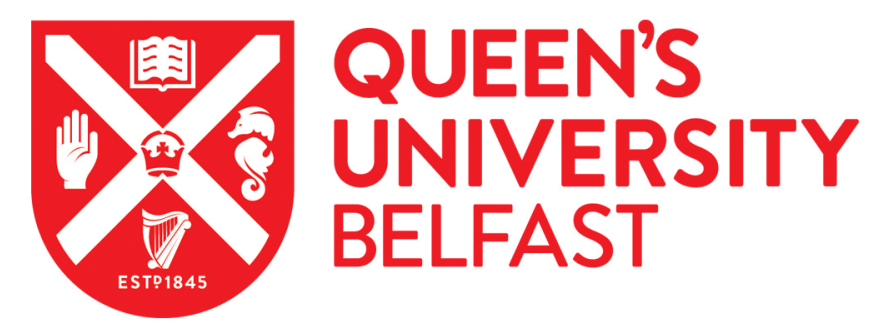

\title{
Specifying An Efficient Renewable Energy Feed-in Tariff
}

Farrell, N., Devine, M. T., Lee, W. T., Gleeson, J. P., \& Lyons, S. (2017). Specifying An Efficient Renewable Energy Feed-in Tariff. The Energy Journal, 53-75. https://doi.org/10.5547/01956574.38.2.nfar

\author{
Published in: \\ The Energy Journal
}

Document Version:

Publisher's PDF, also known as Version of record

Queen's University Belfast - Research Portal:

Link to publication record in Queen's University Belfast Research Portal

Publisher rights

(C) 2017 The Authors.

This is an open access article published under a Creative Commons Attribution License (https://creativecommons.org/licenses/by/4.0/), which permits unrestricted use, distribution and reproduction in any medium, provided the author and source are cited.

\section{General rights}

Copyright for the publications made accessible via the Queen's University Belfast Research Portal is retained by the author(s) and / or other copyright owners and it is a condition of accessing these publications that users recognise and abide by the legal requirements associated with these rights.

Take down policy

The Research Portal is Queen's institutional repository that provides access to Queen's research output. Every effort has been made to ensure that content in the Research Portal does not infringe any person's rights, or applicable UK laws. If you discover content in the Research Portal that you believe breaches copyright or violates any law, please contact openaccess@qub.ac.uk. 


\title{
Specifying An Efficient Renewable Energy Feed-in Tariff
}

\author{
Niall Farrell, ${ }^{\mathrm{a}}$ Mel T. Devine, ${ }^{\mathrm{b}, \mathrm{c}}$ William T. Lee, ${ }^{\mathrm{b}}$ James P. Gleeson, ${ }^{\mathrm{b}}$ and Seán Lyons ${ }^{\mathrm{c}}$
}

\begin{abstract}
Commonly-employed Feed-in Tariff (FiT) structures result in either investors or policymakers incurring all market price risk. This paper derives efficient pricing formulae for FiT designs that divide market price risk amongst investors and policymakers. With increasing deployment and renewable energy policy costs, a means to precisely apportion this risk becomes of greater importance. Option pricing theory is used to calculate efficient FiT prices and expected policy cost when investors are exposed to elements of market price risk. Expected remuneration and policy cost is equal for all FiTs while policymaker and investor exposure to uncertain market prices differs. Partial derivatives characterise sensitivity to unexpected deviations in market conditions. This sensitivity differs by FiT type. The magnitudes of these effects are quantified using numerical examples for a stylised Irish case study. Based on these relationships, we discuss the conditions under which each policy choice may be preferred.
\end{abstract}

Keywords: Efficient Environmental Policy, Feed-in Tariff, Option Pricing, Renewable Energy, Renewable Energy Support Schemes

http://dx.doi.org/10.5547/01956574.38.2.nfar

\section{INTRODUCTION}

Ambitious renewable energy targets exist at both an international (E.C., 2007) and national (Department of Communications, Energy and Natural Resources, 2011; Department of Energy and Climate Change, 2011) level. As renewables tend to generate electricity at a cost greater than conventional sources, public subsidy is often required to create a viable investment environment (Doherty and O’Malley, 2011; Krozer, 2013). Many support schemes exist to incentivise deployment, including Renewable Portfolio Standards; investment grants and total subsidy schemes; and partial/full exemption from certain taxes and levies (Council of European Energy Regulators, 2015). However, price-based mechanisms such as Feed-in Tariffs (FiTs) have become the preferred renewable energy support mechanism in many markets as they provide greater certainty of remuneration for investors (Burer and Wustenhagen, 2009; IEA and OECD, 2008; Ragwitz et al., 2007), aiding $64 \%$ of all wind and $87 \%$ of all photovoltaic (PV) solar deployment since 2010 (DB Climate Change Advisors , 2009; Jacobs, 2014).

a Corresponding author. Economic and Social Research Institute, Whitaker Square, Sir John Rogerson's Quay, Dublin, Ireland and Department of Economics, Trinity College, Dublin, Ireland. Niall Farrell has since moved to Ireland's Environmental Protection Agency (EPA), but this work was carried out when he was employed by the Economic and Social Research Institute. Thus, it does not reflect the views of the EPA. E-mail: n.farrell@epa.ie

MACSI, Department of Mathematics and Statistics, University of Limerick, Limerick, Ireland.

Economic and Social Research Institute, Whitaker Square, Sir John Rogerson's Quay, Dublin; Ireland and Department of Economics, Trinity College, Dublin, Ireland.

The Energy Journal, Vol. 38, No. 2. Copyright (C) 2017 by the IAEE. All rights reserved. 
FiTs usually take the form of a fixed price or constant premium. A fixed-price FiT removes investor exposure to low market prices and transfers the associated risk to the policymaker as a risk of excessive subsidy cost. Effectively managing this risk is of greater importance as policy costs grow in magnitude (Bollino, 2009; Neuhoff et al., 2013; Chawla and Pollitt, 2013; Farrell and Lyons, 2015). One solution is to offer a constant premium regime, otherwise known as a Feed-in Premium (Gallego-Castillo and Victoria, 2015; Kitzing, 2014). This removes policymaker risk by guaranteeing a fixed cost per unit of electricity. However, investors are exposed to the full impact of market price fluctuations. Transferring all market price risk to investors may be undesirable as the effectiveness of FiT regimes has been attributed to their risk-reducing properties (IEA and OECD, 2008).

FiTs that incorporate both certain and uncertain elements may balance these concerns by offering an intermediate division of market price risk. This paper analytically specifies feed-in tariffs that incorporate varying degrees of market price exposure for investors and consumers. Using variants of price floor, shared upside and cap and floor FiT regimes, this is carried out by estimating a price for the fixed portion that incorporates the expected value of the uncertain portion. This has not been addressed in the literature. Kim and Lee (2012) and Kopsakangas-Savolainen and Svento (2013) compare renewable energy policies using simulation methods but do not specify a tool to efficiently define structures that apportion market price risk. An analytical formulation of efficient FiT specification would both provide a tool for policymakers and give insight into preferred conditions for different FiT configurations.

An appropriate theoretical framework is required to adequately characterise the strategic interaction between policymakers and investors when setting a FiT price. This paper follows the electricity pricing analysis of Woo (1988) by drawing on sequential game theory (Kalkuhl et al., 2012; Chang et al., 2013). Option pricing theory is used to value FiTs with both certain and uncertain elements of remuneration as they share traits similar to European 'call' options. A European call option gives the buyer the right, but not the obligation, to buy an underlying asset (e.g. electricity) at a guaranteed 'strike' price (e.g. the guaranteed FiT price floor) at a particular time in the future. Implicit in this option is the possibility to sell at the prevailing market price should it be greater than the guaranteed option 'strike' price. A number of option pricing theories have been developed to estimate the value of such an arrangement (e.g. Black and Scholes, 1973; Keppo and Rasanen, 1999; Overdahl and Matthews, 1988; Pickles and Smith, 1993; Smith, 2005).

Pickles and Smith (1993) have used a binomial lattice option pricing approach to value undeveloped petroleum reserves whilst Smith (2005) has derived formulas to calculate the value of an option for repeated drilling in petroleum exploration. Overdahl and Matthews (1988) have drawn on option pricing theory to forecast crude oil prices whilst Keppo and Rasanen (1999) have used option pricing to price retail electricity tariffs when consumption and wholesale price is uncertain. Lyle and Elliott (2009) develop a model to price electricity derivatives which draws on that of Black and Scholes (1973). The model of Lyle and Elliott (2009) prices derivatives under the physical or real world measure instead of the risk-neutral measure due to the incompleteness of electricity markets. This paper follows this approach and prices options according to these physical or real-world measures. In an environmental context, Chambers et al. (1994) have used option pricing theory to compare the value of an ecological option to conserve against the value of national debt reduction, whilst Conrad (2000) have used option pricing to identify optimal timing of wilderness preservation, extraction or development.

This paper proceeds as follows. The modelling framework is outlined in Section 2. This draws together these separate fields of FiT policy design, game theory in renewable energy invest- 
ment and option pricing theory. Section 3 presents optimal pricing rules for 3 classes of FiT; constant premium, shared 'upside' and cap \& floor policy structures. Each of these tariff designs incorporate varying degrees of market uncertainty and these analytical derivations are the primary contribution to the understanding of FiT policy design offered by this paper.

Section 4 quantifies the sensitivity of each policy specification to unexpected market price outcomes, providing a further tool for FiT evaluation whilst also giving insight into the conditions under which certain FiT configurations are preferred. Tools presented in this paper are demonstrated using a numerical example in Section 5. This provides quantitative insight into the preceding analytical solutions. Finally, Section 6 offers some concluding comments.

\section{INVESTMENT AND MARKET PRICE MODELS}

\subsection{Investment Model}

FiT design may be modelled as a strategic leader game, where the leader (policymaker) chooses their strategy (FiT price) first with followers (investors) implementing their strategy (investment) conditional on that chosen by the leader (Chang et al., 2013; Fudenberg and Tirole, 1991). The leader is aware of the strategic response of the follower and chooses the FiT price that incentivises the desired quantity of renewable generation. This problem can be solved by first calculating the best response function of the follower (investor), which is then substituted into the decision function of the leader (policymaker).

We assume that a policymaker wishes to incentivise the deployment of $Q_{I}$ units of renewable capacity, which operate during $t$ time periods in a time horizon [1, T]. The market is comprised of $n$ investors who will deploy an aggregate $Q$ units of renewable electricity generation capacity.

During time period 0 , investors evaluate the investment decision of total discounted revenue less the total capital and discounted operating costs. Capital costs are incurred in time period 0 and all operation and maintenance costs are incurred annually for $T$ time periods thereafter. $C$ is the total cost of installing one unit of renewables capacity, with $Q$ representing the number of units installed. The total cost of installing $Q$ units of electricity is assumed to be equal to the sum of capital $(A)$ and operating $(O)$ costs (including any required return to personnel, capital, etc.), discounted according to a discount rate $r$. Following the literature and many policy implementations to date (Butler and Neuhoff, 2008; Department of Communications, Energy and Natural Resources, 2006; Department of Energy and Climate Change, 2012; BMU, 2012; Rigter and Vidican, 2010), this paper assumes a constant cost, $C$, and thus specifies FiT prices for a constant state of technological development. For each cost value there is a single efficient strike price. Factors such as technological change may result in costs and thus strike prices changing through time. This modelling framework must be repeated for each potential cost value to accommodate this. These potential cost values may be estimated using existing methodologies such as a digression rate (e.g. Rigter and Vidican, 2010; Department of Energy and Climate Change, 2012). The use of a single cost value allows the model to be analytically tractable and possible directions of future work may include explicit incorporation and analysis of changing strike prices. For the purposes of this paper, total costs are calculated as follows:

$$
C Q=A Q+\sum_{t=1}^{T} e^{-r t} O Q
$$


During each time period of operation, $G_{t}$ units of electricity are generated, calculated as follows:

$$
G_{t}(Q)=b(Q) u v h
$$

where $h$ is the number of hours per time period $t ; v$ is operational availability net of maintenance and other such outages and $u$ is the capacity factor for initial units. The parameter $b$ reflects the nameplate capacity, augmented to incorporate any change in effective capacity/availability as $Q$ changes. For nonsynchronous generation such as wind, solar and wave, this captures increased curtailment due to increasing levels of installation. General issues such as poorer site and resource availability are also captured. $b(Q)$ and hence $G(Q)$, is assumed to be a concave function. The following general function is used for this demonstration, which can easily be replaced by an alternate specification should it be more appropriate for a given application:

$$
b(Q)=Q_{\max }\left(1-e^{-\gamma Q}\right),
$$

where $Q_{\max }$ is the maximum potential $Q$, whilst $\gamma$ is a parameter controlling the rate of change which must be calibrated to observed data.

Investors wish to maximise profits. Aggregating the decision of $n$ investors, where $\Pi$ represents industry profit when $t \in[1, T]$, the industry-level investment decision is

$$
\max _{Q} \Pi=\sum_{t=1}^{T}\left(P_{t} G_{t}\right)-C Q
$$

An optimal $Q$ is achieved when ${ }^{1}$

$$
\frac{\partial \Pi}{\partial Q}=\sum_{t=1}^{T}\left(P_{t} \frac{\partial G_{t}}{\partial Q}+\frac{\partial P_{t}}{\partial Q} G_{t}\right)-C=0 .
$$

To facilitate closed-form solutions, we assume that investors are risk-neutral, resulting in indifference towards exposure to uncertain market prices. Investment decisions are thus made relative to the discounted expected price. For each trading period, the discounted expected price, $P_{t}$, is dependent on the particular FiT structure chosen. For a constant premium regime, this may be the prevailing market price, $S_{t}$ and a constant premium $X$. For a price floor regime, where investors receive a share of market upside should $S_{t}$ exceed the floor, this may be the $K$ price floor or a predefined portion of the market price $S_{t}$, denoted by $\theta$. Alternatively, if a cap \& floor regime is in place, this may be a price floor $K$, the market price $S_{t}$ or a FiT cap, $\bar{S}$. To meet the $Q_{I}$ target, a policy maker must define a combination of these prices such that the investment decision of (1) will yield $Q_{I}$ units of generation. The policymaker wishes to have the guaranteed price floor $K$ as low as possible because they must pay the difference when $K$ is larger than $S_{t}$. Likewise, the policymaker also wishes $\bar{S}$ and $\theta$ to be as low as possible as the policymaker receives any portion

1. Equation (1) is a necessary but not sufficient condition for optimality. In order for it to be sufficient, we also require, at the optimal $Q, \frac{\partial 2 \Pi}{\partial Q^{2}}<0$, which is the case for the numerical examples described in Section 5 . 
of market upside that the investors do not receive. The different types of FiT policy designs and these relationships are described in more detail in Section 3.

The duration of the FiT may not last for the full life of the renewable plant installed. $T_{1}$ is taken to represent the final period of FiT remuneration, with $P_{t}=e^{-r t} E\left[S_{t}\right]$ when $t>T_{1}$.

The policy maker wishes to minimise the net cost of subsidisation $(F)$, represented by the following price support decision:

$$
\min _{K, \theta, \bar{S}} F=\sum_{t=1}^{T_{1}} f_{t} G(Q)
$$

subject to

$$
Q \geq Q_{I}
$$

and subject to equation (1), where $f_{t}$ is the discounted expected cost to the policymaker of supporting the FiT policy during time $t$. Constraint (3) ensures that the target for installed renewable energy capacity on the system is met while equation (1) ensures that the investors' problem is maximised. Assuming that the objective function in equation (2) is increasing for each of the different REFIT policy parameters $(K, \theta, \bar{S})$, and for $Q$, the policymaker's problem is optimal when equation (1) is evaluated at $Q=Q_{I}$

\subsection{Market Price Model}

Market prices during operational time periods $\left(S_{t}\right)$ are uncertain. Assuming an appropriate stochastic process allows this uncertainty to be incorporated into the expected price values in order to evaluate equation (2) (Skantze et al., 2000; Barlow, 2002). For non-synchronous generation sources especially, FiTs incorporating market prices are often calculated based on the average price over a given time period (Department of Communications, Energy and Natural Resources, 2006; Folketinget Danish Parliament, 2008). Each period's price is weighted according to the amount of electricity generated by the renewable technology during that period (Department of Communications, Energy and Natural Resources, 2006; Devitt and Malaguzzi Valeri, 2011). This shall be referred to as the Volume-Weighted Average Price (VWAP) and is offered for each unit of output generated during that period. The resolution of the time period chosen may vary, with Ireland offering a price floor tariff based on annual timesteps (Department of Communications, Energy and Natural Resources, 2006), whilst Denmark offers a FiT for offshore wind based on annual timesteps (Folketinget Danish Parliament, 2008). Monthly timesteps have also been observed, with Denmark offering a FiT for onshore wind using this methodology (Folketinget Danish Parliament, 2008). For this paper, annual timesteps are considered. Fleten et al. (2007) have comprehensively reviewed methodologies to model electricity prices in the analysis of renewable energy investment (Pindyck, 1999; Pinkdyck, 2001; Schwartz and Smith, 2000) finding Geometric Brownian Motion (GBM) appropriate. This is because renewable energy investment is a long-term investment and thus long term price trends are of importance, even when analysing investments in markets with electricity prices of hourly, daily or monthly fluctuations. Thus, results are of negligable sensitivity to intraannual variability (Pindyck, 1999; Pinkdyck, 2001; Schwartz and Smith, 2000). Given this finding, GBM has been employed in many circumstances for the modelling of long-term electricity price processes of annual timesteps (e.g. Wickart and Madlener, 2007; Yang and Blyth, 2007; Heydari 
et al., 2012; Siddiqui and Maribu, 2009; Siddiqui and Fleten, 2010; Zhu, 2012). Following this convention, along with modelling in the context of an annual timestep, GBM is chosen to model annual electricity prices in this paper. Indeed, GBM also has the added advantage of allowing for tractable and closed-from solutions for the tariffs modelled in this work. Extending this model to consider alternate timesteps and thus alternate price processes will be the subject of further study.

GBM may be used to model commodity prices or financial derivatives which contain a degree of random fluctuation. The parameters of this process are $\mu$, which is the drift or average trend of growth; $\sigma$ which is the volatility around the average trend; and $d w$ which is an increment of a Wiener process. The Stochastic Differential Equation (SDE) for a GBM price process is given by equation (4) (Shreve et al., 2004):

$$
d S=\mu(Q) S d t+\sigma S d w
$$

where $\mu(Q)=\bar{\mu}+\eta e^{-\kappa Q}$. The parameter $\bar{\mu}$ represents the rate of growth when the system is saturated with wind, while $\bar{\mu}+\eta$ represents the rate of growth when there is no wind (i.e. $\mathrm{Q}=0$ ). $\kappa$ determines the elasticity of the rate of growth with respect to change in Q. Both $\eta$ and $\kappa$ are scaling parameters and $\eta e^{-\kappa Q}$ may be calibrated such that the rate of growth represents the appropriate impact. The parameter $\eta e^{-\kappa Q}$ is chosen as it allows the dependence of the price on $\mathrm{Q}$ to be calibrated with some flexibility.

Equation (4) shows that the drift in this GBM process depends on the amount of renewables installed $(Q)$. This means the exact rate of growth, and hence the expected VWAP, is endogenous to the investors' problem as well as the overall optimisation problem. VWAPs are modeled this way because the 'merit order effect' of certain renewables with no marginal cost (wind, solar, Sensfuß et al. (2008)) will result in lower rates of market price growth as the quantity $Q$ of installed capacity increases.

Electricity is a unique commodity as it cannot be stored and thus demand must equal supply at all moments in time. This characteristic affects the ability to hedge and to profit from arbitrage and so the market for electricity is incomplete (Lyle and Elliott, 2009; Burger et al., 2004; Tsitakis et al., 2006). We follow the approach of Lyle and Elliott (2009), where all options in this paper are priced under the physical or real world measure.

\section{PRICING TARIFFS}

The FiT designs analysed in this paper may be divided into three broad categories, each with varying degrees of exposure to market price fluctuations. First, a constant premium is considered, where investor remuneration consists of the prevailing market price and an additional constant premium (Couture and Gagnon, 2010). This is analogous to the Feed-in Premium in place in many markets (Council of European Energy Regulators, 2015). Second, following the Irish price floor regime (Department of Communications, Energy and Natural Resources, 2006), tariffs that comprise a floor and a percentage share of market 'upside' in excess of this floor are considered. A special case of this category is when no market 'upside' is received by the investor, and they thus receive a fixed price that is completely independent of market prices. A cap \& floor regime is an alternative way to divide market price exposure and the third FiT category considered. Under this regime, the investor receives a guaranteed minimum price. They receive $100 \%$ of the market price should it exceed this floor, but this is capped at a pre-defined rate. The cap \& floor policy design draws on cap mechanisms discussed in the literature (Couture and Gagnon, 2010; Kim and Lee, 2012) along with those considered in certain jurisdictions (e.g. Queensland Competition Authority, 2013). The 


\section{Figure 1: FiT Payment Structures}

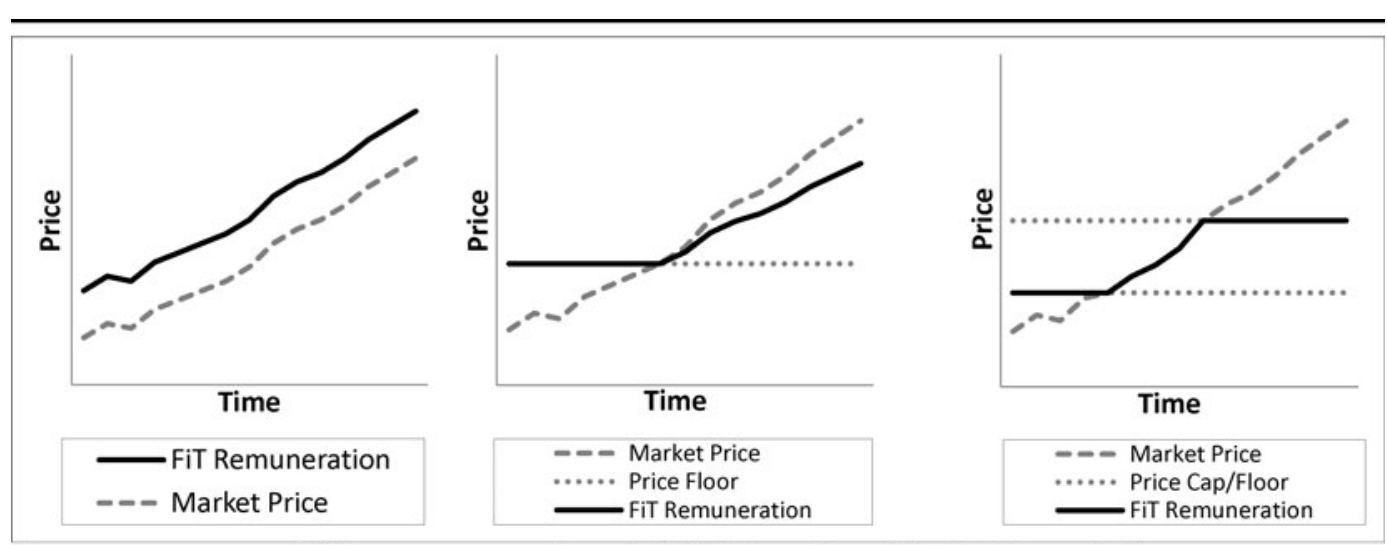

Payment structures: (left) constant premium, (middle) shared upside, (right) cap \& floor.

operation of these tariff designs are outlined graphically in Figure 1. The optimal pricing rules for each of these categories will now be derived, and the relative sensitivities discussed in more detail in section 4.

\subsection{Tariff of Constant Premium}

Equation (1) may be altered to specify a FiT structure where investors receive a constant premium $X$ in excess of the prevailing wholesale market price $S_{t}$ when $t \leq T_{1}$. Assuming that the undiscounted price for each time period $t$, is $V_{t}$, then $V_{t}$ may be denoted

$$
V_{t}=X+S_{t}
$$

The discounted expected price, $P_{t}$, may be specified by calculating the discounted expected value ${ }^{2}$ of $V_{t}$. Thus, $P_{t}=e^{-r t} E\left[V_{t}\right]$. As such, the expected price under this tariff is equivalent to the expected value of $X$ plus the expected value of the market price, $S_{t}$, at time $t$. It is assumed that $S_{0}$ represents $S$ at time period 0 , the initial time period of analysis and the time period at which the investment at time $t$ is evaluated. The expected value of GBM, and hence $S_{t}$, is $S_{0} e^{\mu t}$ (Hull, 2003). Thus, $P_{t}$ when $t \leq T_{1}$ becomes

$$
P_{t}=X e^{-r t}+S_{0} e^{(\mu-r) t}
$$

Using this definition for the price received by the investor and equation (1) leads to a solution for $X$ as follows:

$$
X=\frac{C-\left\{\sum_{t=1}^{T}\left[t S_{0} e^{(\mu-r) t}\right] \frac{\partial \mu}{\partial Q} G_{t}+\left[e^{(\mu-r) t} S_{0}\right] \frac{\partial G_{t}}{\partial Q}\right\} \mid Q_{I}}{\left.\sum_{t=1}^{T_{1}} e^{-r t} \frac{\partial G_{t}}{\partial Q}\right|_{Q_{I}}} .
$$

2. The expected value may be interpreted as the sum of each potential value, multiplied by the probability of occurrence. 
where $\left.\right|_{Q_{I}}$ means that the function is evaluated at $Q_{I}$ and

$$
\begin{aligned}
& \frac{\partial G_{t}}{\partial Q}=Q_{\max } \gamma e^{-\gamma Q} \\
& \frac{\partial \mu}{\partial Q}=-\kappa \eta e^{-\kappa Q} .
\end{aligned}
$$

The cost to the policymaker in offering this FiT $(F)$ may be calculated as the sum of all $X$ payments and may be formally represented as

$$
F=\sum_{t=1}^{T_{1}} X e^{-r t} G_{t}
$$

The solution for an efficient constant $(X)$ premium found in equation (5) may be interpreted as the total generating cost, less market remuneration, averaged over each time period of generation for the marginal generation unit. Output of the marginal unit, evaluated at $Q_{I}$, is represented by $\left.\frac{\partial G_{t}}{\partial Q}\right|_{Q_{I}}$. Equation (5) shows that investor remuneration is highly exposed to any changes in the rate of market price growth, whilst equation (6) shows that policy cost is not. The expected volatility of market prices has no impact on the optimal value of the $X$ premium. This is shown in equation (5). This is because the expected value of GBM is unaffected by the level of volatility (Hull, 2003).

\subsection{Price Floor Plus Shared Market 'Upside'}

A 'shared upside' tariff offers a guaranteed minimum price but allows the investor and policymaker to share additional market remuneration should the market price exceed the guaranteed minimum (i.e. market 'upside'). This tariff structure provides certainty of return for the investor, but also allows them to receive the benefit of any market 'upside' according to a predefined proportional split which may range anywhere between 0\%-100\%. When no market upside is offered to the investor the policy becomes a fixed tariff policy.

The payoff that a renewable energy investor receives at time $t$ when $t \leq T_{1}$ may be characterised as

$$
V_{t}=\max \left(K, K+\theta\left(S_{t}-K\right)\right)
$$

where $\theta$ represents the fractional share of market upside received by the investor. As equation (7) illustrates, modelling of the expected payoff under this FiT structure requires the incorporation of uncertain price processes as outlined in Section 2.2. In the context of the stochastic market prices of Section 2.2, the expected value of equation (7), when $t<T_{1}$, comprises both the expected value of achieving the price floor $K$ or the market price $S_{t}$, conditional on $S_{t}$ being greater than $K$. This is similar to a European 'call' option. The discounted expected price, $P_{t}$ is obtained by calculating the discounted expected value of equation (7):

$$
P_{t}=e^{-r t} E\left[V_{t}\right]=K e^{-r t}\left(1-\theta N\left(d_{2}\right)\right)+\theta S_{0} e^{(\mu-r) t} N\left(d_{1}\right)
$$


where $N($.$) represents the cumulative distribution function of the standard normal distribution while$ definitions for $d_{1}$ and $d_{2}$ can be found in the appendix. ${ }^{3}$ All other variables are as defined as previously.

The solution represented in equation (8) is obtained in a similar manner to the value of a European call option using the Black-Scholes equation; details of this are also provided in the appendix. The expression $\left(1-N\left(d_{2}\right)\right)$ is equivalent to the probability that the option will be exercised. The expression $S_{\tau} e^{(\mu-r) t} N\left(d_{1}\right)$ represents the expected value of a variable that is equal to $S_{t}$ if the option is exercised and zero otherwise. Substituting this value for $P_{t}$ into equation (1) allows us to solve for the optimal $K$ :

$$
K(\theta)=\frac{C-\left.\left(\left[\sum_{t=1 S_{0}}^{T_{1}} e^{(\mu-r) t} \theta N\left(d_{1}\right)\right]\left[\frac{\partial G_{t}}{\partial Q}+t \frac{\partial \mu}{\partial Q} G_{t}\right]\right)\right|_{Q_{I}}+\left.\left(\sum_{t=T_{1}}^{T} S_{0} e^{(\mu-r) t}\left[\frac{\partial G_{t}}{\partial Q}+t \frac{\partial \mu}{\partial Q} G_{t}\right]\right)\right|_{Q_{I}}}{\left.\left[\sum_{t=1}^{T_{1}} e^{(\mu-r) t}\left[1-\theta N\left(d_{2}\right)\right] \frac{\partial G_{t}}{\partial Q}\right]\right|_{Q_{I}}},
$$

while rearranging $(9 \mathrm{a})$ gives the optimal $\theta$ :

$$
\theta(K)=\frac{C-\left(\sum_{t=T_{1}}^{T} S_{0} e^{(\mu-r) t}\left[\frac{\partial G_{t}}{\partial Q}+t \frac{\partial \mu}{\partial Q} G_{t}\right]\right)+\left(\left.\sum_{t=1}^{T_{1}} K e^{-r t} \frac{\partial G_{t}}{\partial Q}\right|_{Q_{I}}\right)}{\left.\sum_{t=1}^{T_{1}}\left(S_{0} e^{(\mu-r) t} N\left(d_{1}\right)\left[\frac{\partial G_{t}}{\partial Q}+t \frac{\partial \mu}{\partial Q} G_{t}\right]-K e^{-r t} N\left(d_{2}\right) \frac{\partial G_{t}}{\partial Q}\right)\right|_{Q_{I}}} .
$$

Equation (9a) may be used to calculate an efficient price floor $K$ that must be used with a given $\theta$, whilst equation (9b) gives the efficient $\theta$ that must be used with a given price floor $K$. This framework may also be used to calculate the cost of the FiT programme to the policymaker. For time period $t$, the cost of the FiT may be defined as

$$
f_{t}=\max \left(0, K-S_{t}\right)-(1-\theta) \max \left(0, S_{t}-K\right)
$$

while the discounted expected cost of the FiT is:

$$
E F_{t}=e^{-r t} E\left[f_{t}\right]=K e^{-r t}-S_{0} e^{(\mu-r) t}+\theta\left(S_{0} e^{(\mu-r) t} N\left(d_{1}\right)-K e^{-r t} N\left(d_{2}\right)\right),
$$

which is derived in the appendix. Equation (9a) shows that the optimal price $K$ is influenced by the probability of achieving either the market price $S_{t}$ or the guaranteed price $K$, which will change as $K$ changes. In practice, an iterative procedure may be used to calculate efficient $K$ and $\theta$ combinations for a number of assumed $K$ values using equations (9a) and (9b).

When $\theta=0$, remuneration is fixed and an efficient $K$ is completely independent of the stochastic market process derived in Section 2.2. In such circumstances, equation (9a) may be interpreted as the total cost of generation divided by the total units generated. When $\theta \neq 0$, the efficient price floor $K$ is determined by the $\theta$ value chosen. A larger $\theta$ results in a larger negative term in the numerator of (9a), along with a larger $\theta$ term in the denominator, results in a smaller value for the optimal $K$, holding everything else constant. This results in an inverse relationship 
between efficient $\theta$ and $K$ values, where a trade-off exists with respect to the degree of market upside a policymaker is willing to offer in exchange for a reduced guaranteed price premium $K$.

Thus, there is a unique locus of $\theta$ and $K$ combinations, with one efficient $K$ for each $\theta$, holding all other variables constant. The following derivative provides a means to quantify the shape of this locus and thus the sensitivity of $\theta$ to a change in the guaranteed price floor, $K$, whilst holding investor profit (П) constant:

$$
\left.\frac{\partial K}{\partial \theta}\right|_{\Pi}=-\frac{\sum_{t=1}^{T_{1}}\left[S_{0} e^{(\mu-r) t} N\left(d_{1}\right)-K e^{-r t} N\left(d_{2}\right)\right] G_{t}}{\sum_{t=1}^{T_{1}} e^{-r t}\left[1-\theta N\left(d_{2}\right)\right] G_{t}} \leq 0 .
$$

\subsection{Price-floor FiT with Cap}

A cap \& floor tariff is a variable tariff that offers a guaranteed minimum price but instead of sharing a fixed portion of all market upside, the investor receives the entire amount of remuneration up to an upper limit or 'cap'. Should the market price exceed this cap, the investor receives the cap price and the policymaker receives market remuneration exceeding the cap. Denoting the cap as $\bar{S}$, the price received by the investor during time period $t$ when $t<T_{1}$ may be characterised as

$$
V_{t}=\max \left(K, \min \left(S_{t}, \bar{S}\right)\right)
$$

When $t<T_{1}$, the discounted expected price, $P_{t}$, may be obtained by calculating the discounted expected value for $V_{t}$ :

$$
P_{t}=e^{-r t} E\left[V_{t}\right]=K e^{-r t}\left(1-N\left(d_{2}\right)\right)+S_{0} e^{(\mu-r) t}\left(N\left(d_{1}\right)-N\left(d_{3}\right)\right)+\bar{S} e^{-r t} N\left(d_{4}\right),
$$

which is derived in the appendix while $d_{1}, d_{2}, d_{3}$, and $d_{4}$ are also all defined in the appendix. Substituting this value for $P_{t}$ into equation (1) allows us to solve for the optimal $K$ :

$$
\begin{aligned}
K(\bar{S})= & \frac{C-\left.\left\{\sum_{t=1}^{T_{1}}\left[S_{0} e^{(\mu-r) t}\left(N\left(d_{1}\right)-N\left(d_{3}\right)\right)\right]\left[\frac{\partial G_{t}}{\partial Q}+t \frac{\partial \mu}{\partial Q} G_{t}\right]+\left[\bar{S} e^{-r t} N\left(d_{4}\right)\right] \frac{\partial G_{t}}{\partial Q}\right\}\right|_{Q_{I}}}{\left.\sum_{t=1}^{T_{1}}\left[e^{-r t}\left(1-N\left(d_{2}\right)\right) \frac{\partial G_{t}}{\partial Q}\right]\right|_{Q_{I}}} \\
& \frac{-\left.\sum_{t=T_{1}}^{T}\left\{S_{0} e^{(\mu-r) t}\left[\frac{\partial G_{t}}{\partial Q}+t \frac{\partial \mu}{\partial Q} G_{t}\right]\right\}\right|_{Q_{I}}}{\left.\sum_{t=1}^{T_{1}}\left[e^{-r t}\left(1-N\left(d_{2}\right)\right) \frac{\partial G_{t}}{\partial Q}\right]\right|_{Q_{I}}}
\end{aligned}
$$

while rearranging (10a) gives the optimal $\bar{S}$ :

$$
\begin{aligned}
\bar{S}(K)= & \frac{C-\left\{\sum_{t=1}^{T_{1}}\left[S_{0} e^{(\mu-r) t}\left(N\left(d_{1}\right)-N\left(d_{3}\right)\right)\right]\left[\frac{\partial G_{t}}{\partial Q}+t \frac{\partial \mu}{\partial Q} G_{t}\right]+\left[K e^{-r t}\left(1-N\left(d_{2}\right)\right)\right] \frac{\partial G_{t}}{\partial Q}\right\} \mid Q_{I}}{\left.\sum_{t=1}^{T_{1}}\left[e^{-r t} N\left(d_{4}\right) \frac{\partial G_{t}}{\partial Q}\right]\right|_{Q_{I}}} \\
& \frac{-\left.\sum_{t=T_{1}}^{T}\left\{S_{0} e^{(\mu-r) t}\left[\frac{\partial G_{t}}{\partial Q}+t \frac{\partial \mu}{\partial Q} G_{t}\right]\right\}\right|_{Q_{I}}}{\left.\sum_{t=1}^{T_{1}}\left[e^{-r t} N\left(d_{4}\right) \frac{\partial G_{t}}{\partial Q}\right]\right|_{Q_{I}}}
\end{aligned}
$$


For a cap \& floor policy, the cost of the FiT at time $t$ is

$$
f_{t}=\max \left(0, K-S_{t}\right)-\max \left(0, S_{t}-\bar{S}\right)
$$

while the discounted expected cost of the FiT is:

$$
E F_{t}=e^{-r t} E\left[f_{t}\right]=K e^{-r t}\left(1-N\left(d_{2}\right)\right)-S_{0} e^{(\mu-r) t}\left(1-N\left(d_{1}\right)\right)-S_{0} e^{(\mu-r) t} N\left(d_{3}\right)+\bar{S} e^{-r t} N\left(d_{4}\right) .
$$

This solution is derived in full in the appendix. ${ }^{4}$

Analogous to the previously discussed interpretations of $\left(1-N\left(d_{2}\right)\right)$ and $S_{0} e^{(\mu-r)(t)} N\left(d_{1}\right)$ (Hull, 2003, for example), the expression $S_{0} e^{(\mu-r)(t)} N\left(d_{3}\right)$ represents the expected value of a variable that is equal to $S_{t}$ if the market price is greater than $\bar{S}$ and zero otherwise. As such, $S_{0} e^{(\mu-r) t}\left(N\left(d_{1}\right)-N\left(d_{3}\right)\right)$ represents the expected value of a variable that is equal to $S_{t}$ if the market price is within the cap \& floor 'collar' and zero otherwise. $N\left(d_{4}\right)$ represents the expected probability of exceeding $\bar{S}$. These relationships characterise how investors and policymakers share exposure to market prices. An increase in $K$ results in smaller value for $S_{0} e^{(\mu-r)(t)} N\left(d_{1}\right)$ and a greater value for $S_{0} e^{(\mu-r)(t)} N\left(d_{3}\right)$. As a result, $S_{0} e^{(\mu-r) t}\left(N\left(d_{1}\right)-N\left(d_{3}\right)\right)$ will fall and thus the degree to which investors are exposed to market price uncertainty falls with an increase in $K$, holding everything else constant.

However, equations (10a) and (10b) also show that there is an inverse relationship between efficient $K$ and $\bar{S}$ values, with a higher $K$ resulting in a lower $\bar{S}$. As efficient $K$ and $\bar{S}$ values are inversely related, so too is investor and policymaker market price exposure. This is similar to the shared upside regime, however the pattern of this exposure differs. The implications of this difference for policy choice are analysed in greater detail in Sections 4 and 5.

Similar to the shared upside regime, a unique locus of efficient $K$ and $\bar{S}$ pairings exists. The shape of this locus and thus sensitivity of this relationship may be quantified by the following partial derivative:

$$
\left.\frac{\partial K}{\partial \bar{S}}\right|_{\Pi}=-\frac{\sum_{t} e^{-r t} N\left(d_{4}\right) G_{t}}{\sum_{t} e^{-r t}\left[1-N\left(d_{2}\right)\right] G_{t}} \leq 0 .
$$

\section{SENSITIVITY TO CHANGE IN UNDERLYING PARAMETERS}

Section 3 has derived formulae for efficient FiT specification. The derived solution for each policy option is optimal in expectation. Should the market price model parameters $(\mu$ and $\sigma)$ not evolve as expected, then the eventual levels of policy cost and profit ${ }^{5}$ may be over or under estimated. Understanding the sensitivity each policy specification may have with respect to changes in these underlying parameters is an important consideration for both investors and policymakers. Formulae to analyse this sensitivity when $t \leq T_{1}{ }^{6}$ will now be presented.

4. Appendix available online at http://works.bepress.com/niall_farrell/

5. The outcome of changes in profitability are determined by whether this is revealed before or after the investment decision has been made. If after, the quantity deployed remains unaffected and investor profitability changes. If before, the quantity deployed may change. We assume the former for the following discussion, with the latter addressed in Section 5.4 .1

6. The expected value of remuneration when $t>T_{1}$ is the same for all policy options. As the purpose of this section is 
The following derivatives outline the impact that differences between the expected and actual specified rates of market price growth $(\mu)$ may have on the eventual rate of investor profit:

$$
\begin{aligned}
& \text { XPremium: } \frac{\partial \Pi}{\partial \mu}=\quad \sum_{t=1}^{T_{1}} t S_{0} e^{(\mu-r) t} G_{t} \quad \geq 0, \\
& \text { Shared Upside }: \frac{\partial \Pi}{\partial \mu}=\quad \sum_{t=1}^{T_{1}} t S_{0} e^{(\mu-r) t} G_{t} \theta N\left(d_{1}\right) \quad \geq 0 \text {, } \\
& \text { Cap \&floor: } \frac{\partial \Pi}{\partial \mu}=\sum_{t=1}^{T_{1}} t S_{0} e^{(\mu-r) t} G_{t}\left(N\left(d_{1}\right)-N\left(d_{3}\right)\right) \geq 0 \text {. }
\end{aligned}
$$

Defining the cost of policy as ' $F$ ', the impact changes in market price growth may have on policy cost are

$$
\begin{array}{cc}
\text { X Premium }: \frac{\partial F}{\partial \mu}= & 0, \\
\text { Shared Upside }: \frac{\partial F}{\partial \mu}= & -\sum_{t=1}^{T_{1}} t S_{0} e^{(\mu-r) t} G_{t}\left[1-\theta N\left(d_{1}\right)\right] \quad \leq 0, \\
\text { Cap \&floor }: \frac{\partial F}{\partial \mu}= & -\sum_{t=1}^{T_{1}} t S_{0} e^{(\mu-r) t} G_{t}\left(1-N\left(d_{1}\right)+N\left(d_{3}\right)\right) \leq 0 .
\end{array}
$$

Exposure to market price growth is represented by the term $t S_{0} e^{(\mu-r) t} G_{t}$. For each tariff structure, this term is weighted by a term corresponding to the probability of market price exposure. For investor remuneration, the constant premium tariff has a probability of exposure equal to one, for shared upside this is $\theta N\left(d_{1}\right)$ and for cap \& floor policies this is $N\left(d_{1}\right)-N\left(d_{3}\right)$. For policy cost, the constant premium tariff has a probability of exposure equal to zero, for shared upside this is $1-\theta N\left(d_{1}\right)$ and for cap \& floor policies this is $1-N\left(d_{1}\right)+N\left(d_{3}\right)$.

The impact unexpected changes in market price volatility may have on investor remuneration are

$$
\begin{array}{cc}
\text { XPremium }: \frac{\partial \Pi}{\partial \sigma}= & 0, \\
\text { Shared Upside }: \frac{\partial \Pi}{\partial \sigma}= & \sum_{t=1}^{T_{1}} \sqrt{t} S_{0} e^{(\mu-r) t} G_{t} \theta N^{\prime}\left(d_{1}\right) \quad \geq 0, \\
\text { Cap \& floor }: \frac{\partial \Pi}{\partial \sigma}=\sum_{t=1}^{T_{1}} \sqrt{t} S_{0} e^{(\mu-r) t} G_{t}\left(N^{\prime}\left(d_{1}\right)-N^{\prime}\left(d_{3}\right)\right),
\end{array}
$$

while the impact on policy costs are

$$
\begin{array}{cc}
\text { XPremium }: \frac{\partial F}{\partial \sigma}= & 0, \\
\text { Shared Upside }: \frac{\partial F}{\partial \sigma}= & \sum_{t=1}^{T_{1}} \theta S_{0} \sqrt{t} e^{(\mu-r) t} G_{t} N^{\prime}\left(d_{1}\right) \quad \geq 0, \\
\text { Cap \& floor }: \frac{\partial F}{\partial \sigma}=\sum_{t=1}^{T_{1}} S_{0} \sqrt{t} e^{(\mu-r) t} G_{t}\left(N^{\prime}\left(d_{1}\right)-N^{\prime}\left(d_{3}\right)\right) .
\end{array}
$$

to compare sensitivity of each policy option, the analysis is limited to the relevant portion of remuneration that differs under different policy options. As such, remuneration when $t>T_{1}$ is thus omitted from this section of analysis. 
A change in the rate of volatility is represented by the parameter $\sqrt{t} S_{0} e^{(\mu-r) t} G_{t}$. For both investor remuneration and policy cost, the exposure is represented by similar weighting terms; $\theta N^{\prime}\left(d_{1}\right)$ and $N^{\prime}\left(d_{1}\right)-N^{\prime}\left(d_{3}\right)$ for a shared upside and cap/floor policy respectively.

A number of important findings emerge. First, investors under a constant premium bear the entire degree of uncertainty due to changes in market price parameters. A change in the rate of market price growth affects the expected profitability of a constant premium regime, with the entire degree of market price change affecting profitability. Policy cost is insensitive to such a change. Expected policy cost and investment profitability are insensitive to changes in volatility under a constant premium regime as the expected value of GBM is insensitive to the rate of volatility.

Second, we see that an inverse relationship exists with respect to changes in market price growth, with an increase in the rate of growth leading to increased profitability and reduced policy cost for both shared upside and cap \& floor policies. For each policy, greater exposure to market price changes (through a lower $K$ and thus higher $\theta / \bar{S}$ ) increases investor sensitivity to this change, while lowering policymaker sensitivity. Conversely, the rate of change in policy cost due to a change in the rate of volatility is the same as the rate of change of investor remuneration.

Third, the relative sensitivity of shared upside and cap \& floor policies to changes in market parameters may be identified. This may be illustrated by comparing sensitivities of profitability to the rate of market price volatility. Specifying the same $K$ for both shared upside and cap \& floor policies implies that $N^{\prime}\left(d_{1}\right)$ is the same. Relative sensitivity may thus be compared. If $\theta N^{\prime}\left(d_{1}\right)$ is equal to $N^{\prime}\left(d_{1}\right)-N^{\prime}\left(d_{3}\right)$, then the impact on remuneration will be the same. If $\theta N^{\prime}\left(d_{1}\right)>$ $N^{\prime}\left(d_{1}\right)-N^{\prime}\left(d_{3}\right)$, then the shared upside policy is more sensitive.

While the formulations of the partial derivatives defined in this section give insight into the behaviour of cost and profitability due to changes in the underlying market parameters, we gain little insight into the relative magnitudes of these effects. These will be explored through a numerical application in Section 5.

\section{A NUMERICAL APLICATION}

\subsection{Case Study Parameters}

We apply the formulae derived in Sections 3 and 4 to analyse a stylised case study. FiT policy to support wind generation in Ireland is considered, with parameters and their sources outlined in Table 1. It is assumed that a wind turbine is operational for 20 years. FiT remuneration is received for 15 years, replaced by the expected VWAP during periods 16-20, with capacity targets $\left(Q_{I}\right)$ and maximum capacity values $\left(Q_{\max }\right)$ sourced from the literature. The capacity factor and rate of device availability are assumed constant for all capacity, with the $b(Q)$ parameter of equation (1) reflecting changes in the level of curtailment alone. The $\gamma$ parameter is chosen such that the level of curtailment measured at $Q_{I}$ approximates that of McGarrigle et al. (2013) under a scenario of low offshore wind capacity and a 75\% System Non-Synchronous Penetration (SNSP) limit.

$S_{0}$ approximates the 2010 Irish VWAP (Doherty and O'Malley, 2011; SEMO, 2011). Rates of growth $(\mu)$ and volatility $(\sigma)$ are chosen such that the distribution of future VWAP values correspond to those outlined in Doherty and O'Malley (2011). Scaling parameters $\kappa$ and $\eta$ are chosen such that the difference in the SMP in 2020 when no wind and a $4630 \mathrm{MW}$ wind capacity $\left(Q_{I}\right)$ is in place is the same difference that was observed by IWEA (2011) when calculating a no wind and $45 \% 2020$ penetration. For each of the numerical examples described in this section, it was found that $\left.\frac{\partial^{2} \Pi}{\partial Q^{2}}\right|_{Q_{I}}<0$, i.e, the investors' profit was at a maximum at $Q_{I}$. 
Table 1: Baseline Parameters

\begin{tabular}{lr}
\hline \hline Parameter & Value \\
\hline Capital Cost (Wind, per MW) & $€ 1.76 \mathrm{~m}^{a}$ \\
Annual Operations \& Maintenance Cost & $2 \%$ of capital cost \\
SEM Installation target $\left(Q_{I}\right)$ & $4,630 \mathrm{MW}^{b}$ \\
Capacity Factor $(u)$ & $0.35^{a}$ \\
Availability $(v)$ & $0.95^{a}$ \\
Maximum $Q\left(Q_{\max }\right)$ & $16 \mathrm{GW}^{c}$ \\
$\gamma$ & $\left(6.75 \times 10^{-5}\right)^{b}$ \\
Generation during $t\left(G_{t}\right)$ & $12,501,319^{e}$ \\
Long-run electricity Price Growth $(\bar{\mu})$ & $0.0155^{a}$ \\
$\eta$ & $0.01^{e}$ \\
$\kappa$ & $0.001^{d}$ \\
Electricity Price Volatility $(\sigma)$ & $0.13^{a}$ \\
Initial VWAP $\left(S_{0}\right)$ & $€ 52.41^{a}$ \\
Discount Rate $(r)$ & 0.06 \\
\hline
\end{tabular}

Source: ${ }^{a}$ calibrated to Doherty and O'Malley (2011); ${ }^{b}$ calibrated to McGarrigle et al. (2013); ${ }^{c}$ SEAI (2011); ${ }^{d}$ calibrated to IWEA (2011); ${ }^{e}$ own calculation

Table 2: Constant Premium $(X)$ Results

\begin{tabular}{lrr}
\hline & & Value \\
\hline Efficient constant premium $X$ & $€$ & $22.94 / \mathrm{MWh}$ \\
Expected investor profit & $€$ & $1,737 \mathrm{~m}$ \\
Expected policy cost & $€$ & $3,243 \mathrm{~m}$ \\
VaR investor profit & $€$ & $-1,792 \mathrm{~m}$ \\
VaR policy cost & $€$ & $3,243 \mathrm{~m}$ \\
\hline
\end{tabular}

The formulae of Section 3 and Section 4 are applied in this section. To give insight into market price exposure under each policy option, we also employ a Monte Carlo simulation of 10,000 iterations. Computational time was under 2 minutes using a quad-core processor with $8 \mathrm{~GB}$ of RAM. This allows us to calculate the Value at Risk (VaR), the value of cost or remuneration at a particular percentile of potential policy cost or investor profit. The 5 th percentile of investor profit is chosen as a measure of exposure to under-remuneration, whereas the 95th percentile of policy cost is chosen as a measure of exposure to excessive policy cost.

\subsection{Price, Policy Cost and Investor Profit for Each Policy Option}

For the considered case study, a single efficient constant premium $(X)$ of $€ 22.94 / \mathrm{MWh}$ exists (see Table 2). Outlined in Section 3 and illustrated in Figure 2, there exists a locus of efficient price floor and market upside $(\theta)$ combinations for the shared upside regime, and a similar locus of efficient price floor and cap $(\bar{S})$ combinations for the cap \& floor regime. Thus, for each $K$, there is an efficient corresponding share of market upside or cap.

As Section 3 has discussed, we see a negative relationship between $\theta / \bar{S}$ and the corresponding efficient price floor $(K)$. This relationship differs by policy type. For each $\theta$ value under a shared upside policy, investors are exposed to all market prices in excess of the price floor $K$, resulting in a linear relationship between $\theta$ and $K$. However, while a lower price floor $K$ requires a higher $\bar{S}$ to incentivise a $Q_{I}$ level of deployment, there are fewer occurrences of high prices than 


\section{Figure 2: Locus of Efficient FiT Prices}

(a) Shared upside

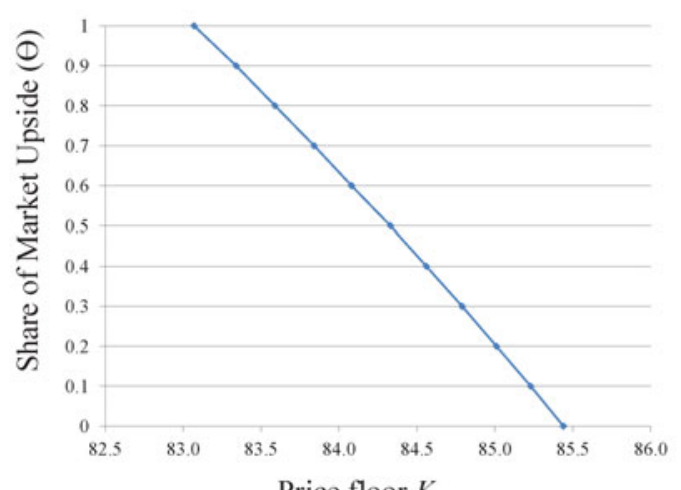

Price floor $K$ (b) Cap \& floor

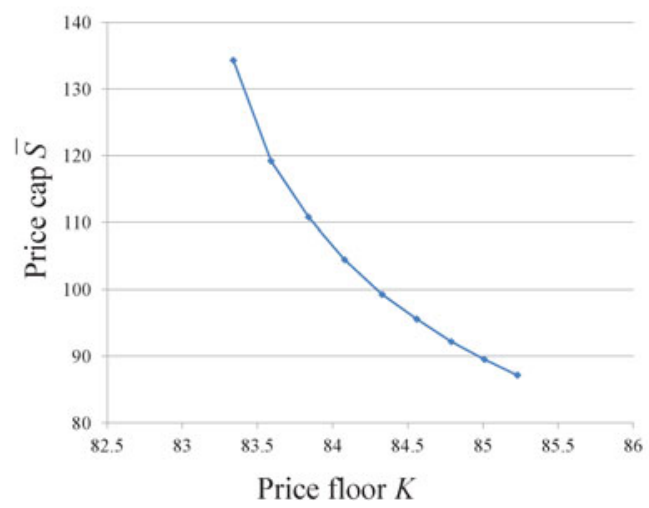

Note: FiT prices calculated using market parameters outlined in Table 1. $\theta$ values are calculated in increments of 0.1 . The floor prices $(K)$ chosen for each analysed cap \& floor policy correspond to the efficient floors derived for each of these $\theta$ values. Thus, results presented in Figures 2(a) and 2(b) are immediately comparable.

low prices. Thus, the cap must grow by a greater amount with each subsequent reduction in the price floor $K$. The non-linear relationship of Figure 2(b) results.

As Section 2 has outlined, investors choose the profit-maximising $Q_{I}$ conditional on costs and the expected level of remuneration. Each FiT specification yields the same expected level of remuneration to incentivise the same $Q_{I}$ level of deployment. As policy cost is the difference between market prices and the price guarantee of the FiT policy, and the price guarantee is adjusted to yield the same expected level of remuneration for each FiT specification, expected policy cost is the same for all FiT specifications. This is confirmed by the numerical results presented in Figure 3. By accounting for the value of market upside in the expected level of remuneration, the potential for overcompensation is minimised. This is an important contribution as Doherty and O'Malley (2011) find that the value of market upside is unaccounted for in many markets such as Ireland where a price floor is in place. In such circumstances, the FiT offered is sub-optimal.

While expected profit and costs are equal, exposure to market price uncertainty is not. An increase in the price floor $K$ lessens VaR-measured exposure to potentially low profits. Conversely, a higher $K$ increases policymaker exposure to high policy cost. The magnitude of these effects is almost identical for shared upside and cap \& floor policies. This is in contrast to results for the constant premium $(X)$ policy (Table 2). Policy cost is certain at the expected value, whereas the VaR for investor profit is negative. This demonstrates the substantial degree to which profitability is determined by uncertain market prices under a constant premium regime and the ability of the presented shared upside and cap \& floor policies to identify intermediate divisions between investors and consumers.

Should policymakers wish to minimise their exposure to excessive policy costs, Table 2 and Figure 3 show that the constant premium policy has the lowest VaR for policy cost and is thus the preferred choice. The policymaker may wish to choose an intermediate division of market price uncertainty to balance their exposure to excessive policy cost against the possibility of investor under-remuneration and thus possible failure to achieve policy targets. Figure 3 presents a spectrum of VaR-quantified market price exposure for shared upside and cap \& floor policies to carry this out. For example, should policymakers be unwilling to incur a VaR of greater than $€ 5$.8bn, whilst 


\section{Figure 3: Expected Profit and policy cost}

(a) Investor Profit

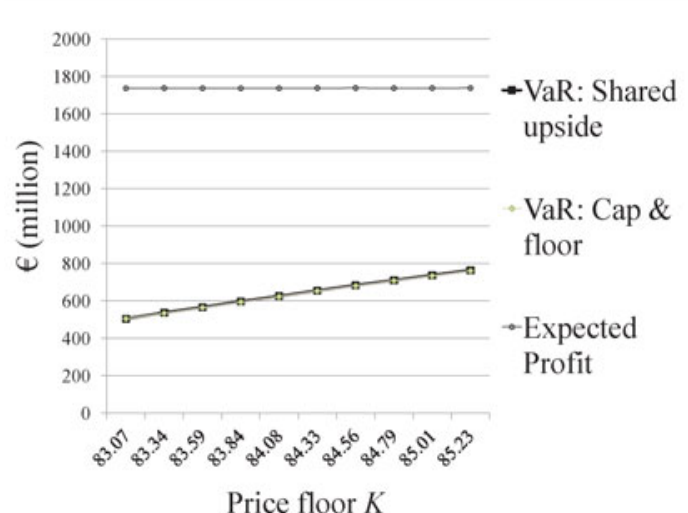

(b) Policy cost

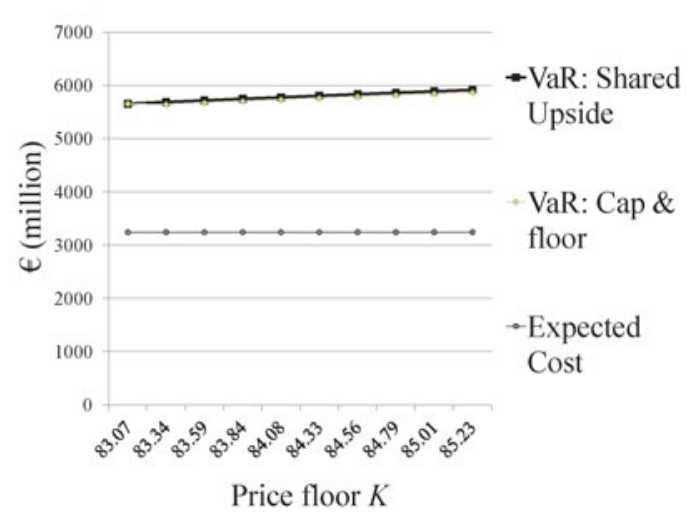

Note: Results calculated using market parameters outlined in Table 1. Investor Profit and policy cost values are industry totals. 'VaR' is calculated at a particular percentile of potential policy cost or investor profit. The 5th percentile of investor profit is chosen as a measure of exposure to under-remuneration, whereas the 95th percentile of policy cost is chosen as a measure of exposure to excessive policy cost.

also wishing to minimise investor exposure to market price uncertainty, then a shared upside policy where $K=84.33(\theta=0.5)$ is preferred. A similar approach may be taken when determining preferred implementation of all other FiT specifications. This analysis assumes investor indifference towards exposure to uncertain market prices. A comprehensive contextualisation of FiT choice under all circumstances of risk aversion is outside the scope of this paper and is a potential avenue of future work. However, the implications of market price exposure are important to make an informed FiT choice. We offer this insight in Sections 5.3 and 5.4.

\subsection{Quantified Sensitivity to Changes in Underlying Market Parameters and Implications for FiT Type}

While insight has been given into efficient division of market price risk, an efficient choice of FiT design that shares market price exposure (i.e cap \& floor or shared upside) has been less clear. The sensitivities discussed in Section 4 may affect this FiT choice. This section give numerical insight into these sensitivities and, in doing so, consider the implications for FiT choice.

Sensitivities presented in Section 4 are quantified in Figure 4. Expected cost and profit are most sensitive to change under a constant premium regime. A change in the rate of growth has a differing effect on cost and profit for shared upside and cap \& floor policies, however the magnitude of this difference is negligable.

A change in the rate of volatility also has a differing effect on cost and profit for shared upside and cap \& floor policies, with the magnitude of this effect much more considerable. This is because a change in the rate of volatility affects the prevalence of extreme market values. Under a cap \& floor policy, investors are not exposed to prices that exceed the cap, dampening the sensitivity of policy cost and investor remuneration to increases in volatility. A cap \& floor policy is less sensitive to under-remuneration due to lower rates of market price volatility and over-remuneration due to a greater rate of market price volatility. Figure 4(b) shows that changes in the rate of market price volatility do not affect expected policy cost or investor remuneration for a constant premium 


\section{Figure 4: Sensitivity to Changes in Underlying Parameters}

(a) Expected profit: growth rate change

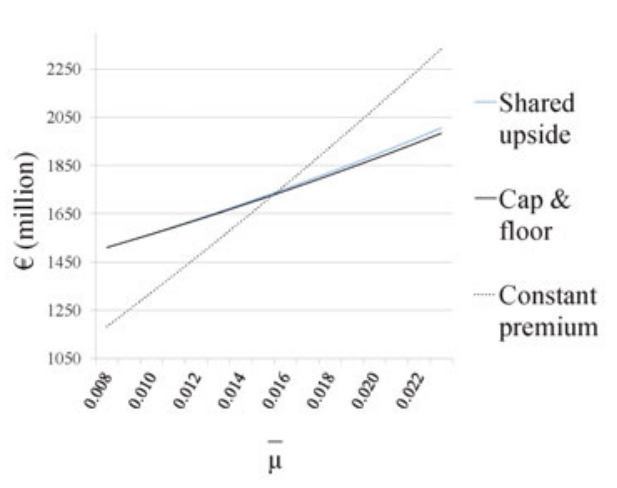

(c) Expected policy cost: growth rate change

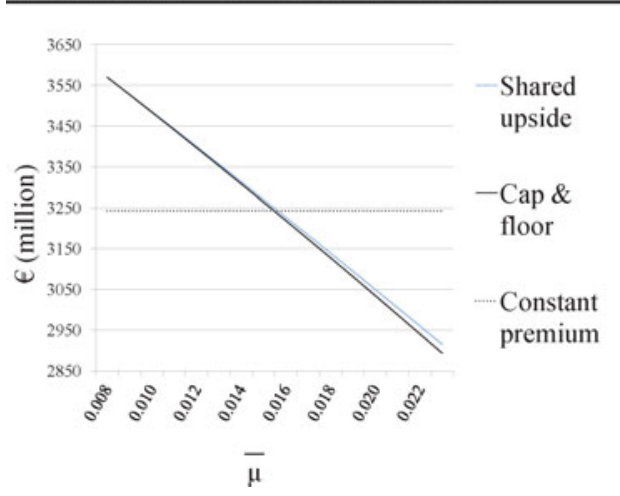

(b) Expected profit: volatility rate change

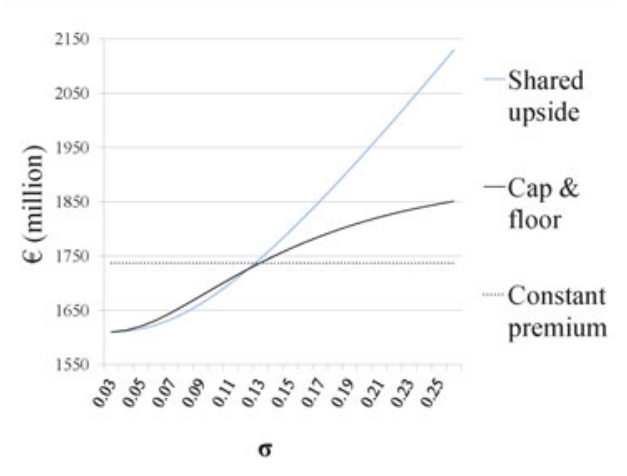

(d) Expected policy cost: volatility rate change

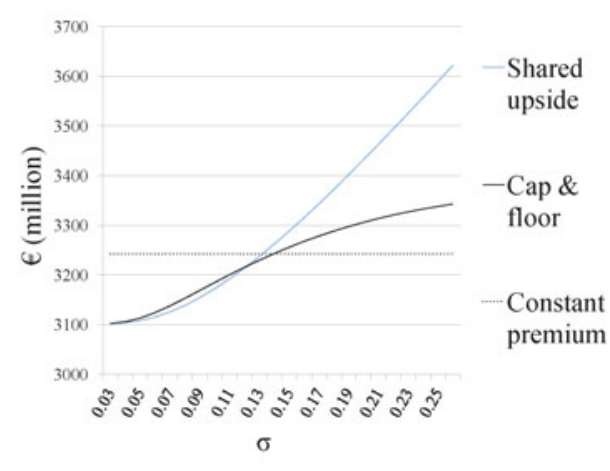

Note: Results calculated using market parameters outlined in Table 1. Investor Profit and policy cost values are industry totals. The shared upside policy is calculated with a price floor $(K)$ of 84.33 and a $\theta$ of 0.5 . The cap \& floor policy is calculated with a price floor $(K)$ of 84.33 and a cap $(\bar{S})$ of 99.26 . As the price floors for both shared upside and cap \& floor policies are the same, results are immediately comparable.

regime as market prices are assumed to follow GBM and the expected value of GBM is unaffected by the level of volatility (Hull, 2003).

Should policymakers wish to share market price exposure, while concerned about sensitivity to changes in the rate of market price growth, there is little discernable difference between the cost of a shared upside or cap \& floor specification. Should this concern be in relation market price volatility, then a cap \& floor policy is preferable to a shared upside policy.

Finally, the sensitivity of shared upside and cap \& floor policies to changes in market price parameters is predicated on the chosen $\theta$ or cap \& floor combination. Shared upside sensitivity is shown in Figure 5 for a number of $\theta$ specifications. This shows the extent to which greater exposure to uncertain market prices gives a greater sensitivity to changes in market parameters. For completeness, sensitivities with respect to policy cost, and cap \& floor sensitivities, are offered in Appendix C. ${ }^{7}$ 
Figure 5: Shared Upside: Sensitivity of Investor Profit to Share of Market Price Exposure

(a) Rate of Market Price Growth

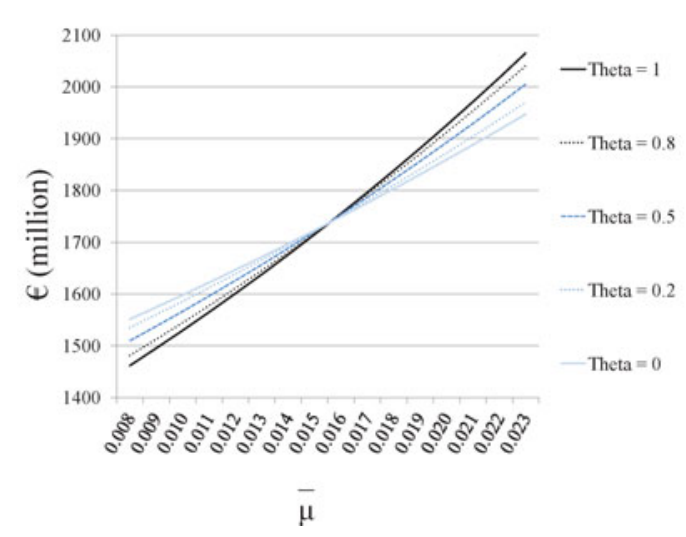

(b) Rate of Market Price Volatility

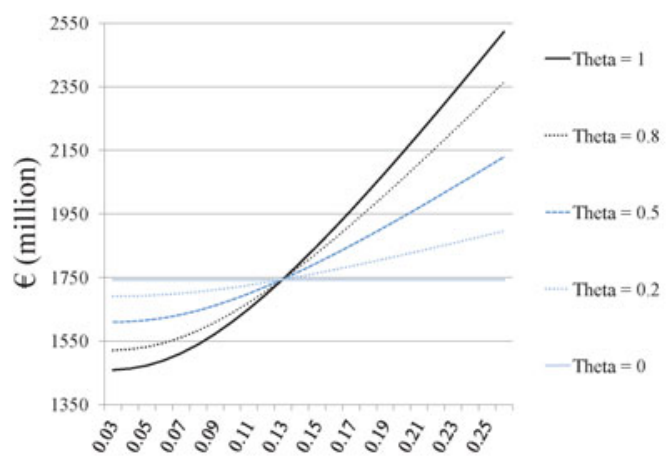

$\sigma$

\subsection{Further Sensitivity Analyses}

\subsubsection{Changes in profitability before investment decision has been made}

Thus far, it has been assumed that ex-post changes in market price parameters occur after the investment decision has been made, and investor profitability suffers but the quantity deployed remains unchanged. Should such changes be identified before the investment decision has been made, then this may affect the quantity of renewables deployed, as shown in Figure 6. Regardless of whether the investor is able to adjust their $Q$ investment decision, these changes will affect policy cost in the manner outlined in Figures 4(b) and 4(c). For example, an increase in the rate of market price growth from 0.0155 to 0.01675 increases expected industry profit by $3 \%$, assuming a shared upside policy where $\theta=0.5$. This will decrease policy cost by $1.9 \%$. Should this change in the rate of growth become apparent before the investor commits to $Q$ level of capacity, then the optimal $Q$ is subject to change according to equation (1), with an increase in the quantity installed from 4630 to 4683 (See Figure 6). Should this change become apparent after the investment decision has been made, then investors will receive supernormal profits and the $Q$ installed will remain the same.

Should the policymaker or investor choose to deviate from the optimal solution, this will result in a change in profitability or cost. The results of Figures 4 and 6 show the investor how much they must change profitability or cost in order to offset an estimated change in the market price parameters.

\subsubsection{Sensitivity change in deployment target $\left(Q_{I}\right)$}

Table 3 shows that the FiT price $K$ grows with a change in the $Q_{I}$ installation target. This is because each subsequent unit is subject to greater curtailment and an added level of remuneration is required for viability of investment. Expected profit and policy cost grow by increasing amounts with every increase in $Q_{I}$. As a higher $K$ is required to incentivise deployment for the marginal unit, this increases infra-marginal rent and thus increases profits and total policy cost. Profit and cost evaluated at the VaR also increases with the $Q_{I}$ installed. While Ireland is an island system and thus curtailment may be greater than elsewhere, this phenomenon may persist in other jurisdictions. 


\section{Figure 6: Sensitivity of quantity deployed $(Q)$ to change in underlying parameters}

(a) Sensitivity of quantity deployed $(Q)$ to change in rate of growth $(\mu)$

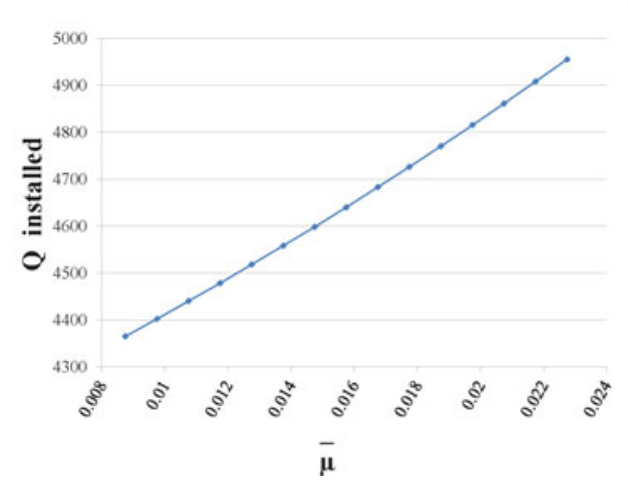

(b) Sensitivity of quantity deployed $(Q)$ to change in rate of volatility $(\sigma)$

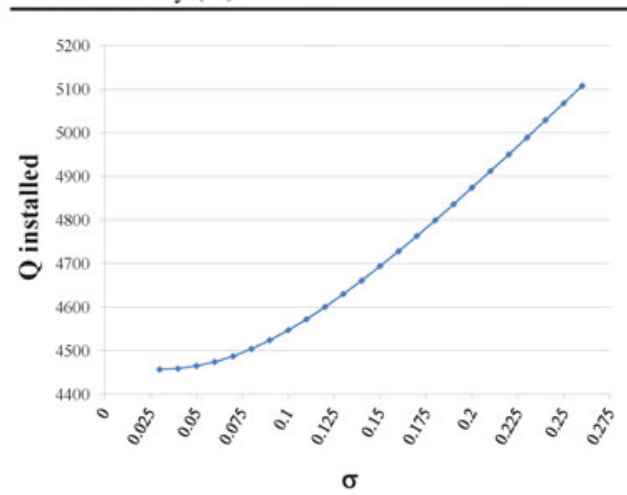

Note: Results calculated using market parameters outlined in Table 1 for a shared upside policy with a price floor $(K)$ of 84.33 and a $\theta$ of 0.5 .

Table 3: Sensitivity to Change in Deployment

\begin{tabular}{rrrrrr}
\multicolumn{7}{c}{ Target $\left(\boldsymbol{Q}_{\boldsymbol{I}}\right)$} \\
\hline \multicolumn{3}{c}{ Expected value } & \multicolumn{2}{c}{ VaR } \\
$Q_{I}$ & $K$ & Profit & Cost & Profit & Cost \\
\hline 3.60 & 77.28 & 1.02 & 1.96 & 0.11 & 3.98 \\
4.63 & 84.33 & 1.74 & 3.24 & 1.46 & 6.50 \\
5.60 & 91.24 & 2.60 & 4.74 & 1.37 & 7.79 \\
\hline
\end{tabular}

Note: Results calculated using market parameters outlined in Table 1 for a shared upside policy with a $\theta$ of 0.5 . and price floor $K$ of 84.33

Table 4: Sensitivity to Change in FiT Duration $\left(T_{1}\right)$

\begin{tabular}{rrrrrrr}
\hline & & \multicolumn{3}{c}{ Expected value } & \multicolumn{2}{c}{ VaR } \\
$T_{1}$ & $K$ & $Q_{I}$ & Profit & Cost & Profit & Cost \\
\hline 10 & 91.8205 & 4.6 & 1.74 & 3.24 & -0.26 & 4.97 \\
15 & 84.3282 & 4.6 & 1.74 & 3.24 & 0.66 & 5.81 \\
20 & 81.03931 & 4.6 & 1.74 & 3.24 & 1.46 & 6.50 \\
\hline
\end{tabular}

Note: Results calculated using market parameters outlined in Table 1 for a shared upside policy with a $\theta$ of 0.5 and price floor $K$ of 84.33 .

To minimise inframarginal rent, policymakers may thus prefer to set FiTs for smaller capacity targets. Table 3 presents results for a shared upside policy, with a similar pattern emerging for other policy specifications.

\subsubsection{Sensitivity to change in FiT duration $\left(T_{1}\right)$}

As the profit-maximising level of deployment is determined by the expected remuneration offered, a change in the duration of FiT policy $\left(T_{1}\right)$ will not affect the discounted expected profit 
or policy cost, but will affect the FiT price offered. A shorter duration means that the required level of profit must be offered over a shorter timespan. Thus a higher FiT price is required. While investors receive a higher FiT, this is over a shorter duration and thus investor exposure to uncertain market prices is greater throughout the duration of the installation. Conversely, policymakers incur a lower $\mathrm{VaR}$, representing the shorter duration for which they may incur excessive policy cost.

\section{CONCLUSION}

Feed-in Tariffs (FiTs) are the preferred policy mechanism to support renewable energy deployment. Commonly employed FiT structures result in either investors or policymakers incurring the full degree of market price exposure. This paper provides an analytical specification of tariff structures that share market price exposure. Sequential decision making in game theory and option pricing theory have been used to derive efficient pricing rules for constant premium, shared upside and cap \& floor FiTs. Partial derivatives are used to quantify sensitivity to ex-post changes in the underlying market parameters. Numerical examples have provided quantitative insight into efficient prices under each regime and the relative magnitude of changes in policy cost and investor profit due to ex-post market changes. These relationships have been used to discuss the prevailing expectations, preferences and market conditions that provide the contextual suitability for each tariff structure.

Alongside providing tools for policy, the findings of this paper provide a modelling platform that may also aid future academic analyses of FiT policy. Assumptions of investor risk neutrality, annual volume weighted average prices and single cost scenarios were required to facilitate a tractable modelling framework. Possible directions for future work may compare findings when these assumptions are relaxed. Nevertheless, this paper provides an important first contribution towards the explicit incorporation of market price exposure in efficient feed-in tariff specification. In in a global energy market characterised by increasing proliferation of low-cost gas, wholesale energy prices are becoming increasingly uncertain. It is in this context that tools to efficiently share this risk are of increasing importance.

\section{ACKNOWLEDGMENTS}

This research is funded by the Programme for Research in Third-Level Institutions (PRTLI) Cycle 5 and co-funded under the European Regional Development Fund (ERDF), Science Foundation Ireland awards 09/SRC/E1780 and 12/IA/1683 and the ESRI Energy Policy Research Centre.

All authors would like to thank participants at the Mannheim Energy Conference 2013; IAEE 2013 European Conference, Dusseldorf; ESRI, UCD and UL internal seminars and the helpful comments of 4 anonymous referees. The usual disclaimer applies.

\section{REFERENCES}

Barlow, M. T. (2002). “A diffusion model for electricity prices.” Mathematical Finance 12(4): 287-298. http://dx.doi.org/ 10.1111/j.1467-9965.2002.tb00125.x.

Black, F. and M. Scholes (1973). "The pricing of options and corporate liabilities." Journal of Political Economy 81(3): 637-654. http://dx.doi.org/10.1086/260062.

BMU (2012). Tariffs, degression, and sample calculations pursuant to the Renewable Energy Sources Act of 4 August 2011 ('EEG 2012'). Berlin:BMU.

Bollino, C. A. (2009). "The willingness to pay for renewable energy sources: the case of Italy with socio-demographic determinants." The Energy Journal 30(2): 81-96. http://dx.doi.org/10.5547/ISSN0195-6574-EJ-Vol30-No2-4. 
Burer, M. J. and R. Wustenhagen (2009). "Which renewable energy policy is a venture capitalist's best friend? Empirical evidence from a survey of international cleantech investors." Energy Policy 37(12): 4997-5006. http://dx.doi.org/10.1016/ j.enpol.2009.06.071.

Burger, M., B. Klar, A. Müller, and G. Schindlmayr (2004). "A spot market model for pricing derivatives in electricty markets.” Quantitative Finance 4: 109-112. http://dx.doi.org/10.1088/1469-7688/4/1/010.

Butler, L. and K. Neuhoff (2008). "Comparison of feed-in tariff, quota and auction mechanisms to support wind power development." Renewable Energy 33(8): 1854-1867. http://dx.doi.org/10.1016/j.renene.2007.10.008.

Chambers, C. M., P. E. Chambers, and J. C. Whitehead (1994). "Conservation organizations and the option value to preserve: an application to debt-for-nature swaps." Ecological Economics 9(2): 135-143. http://dx.doi.org/10.1016/09218009(94)90095-7.

Chang, M.-C., J.-L. Hu, and T.-F. Han (2013). “An analysis of a feed-in tariff in Taiwan's electricity market.” International Journal of Electrical Power \& Energy Systems 44(1): 916-920. http://dx.doi.org/10.1016/j.ijepes.2012.08.038.

Chawla, M. and M. G. Pollitt (2013). "Energy-efficiency and Environmental Policies \& Income Supplements in the UK: Evolution and Distributional Impacts on Domestic Energy Bills.” Economics of Energy \& Environmental Policy 2(1): 21-40. http://dx.doi.org/10.5547/2160-5890.2.1.2.

Conrad, J. M. (2000). "Wilderness: options to preserve, extract, or develop." Resource and Energy Economics 22(3): 205219. http://dx.doi.org/10.1016/S0928-7655(00)00031-2.

Council of European Energy Regulators (2015). Status Review of Renewable and Energy Efficiency Support Schemes in Europe in 2012 and 2013. CEER Status Review of Renewable and Energy Efficiency Support Schemes, C14-SDE-4403 .

Couture, T. and Y. Gagnon (2010). "An analysis of feed-in tariff remuneration models: Implications for renewable energy investment.” Energy Policy 38(2): 955-965. http://dx.doi.org/10.1016/j.enpol.2009.10.047.

DB Climate Change Advisors (2009). Paying for renewable energy: TLC at the right price -Achieving scale through efficient policy design. New York, NY: The Deutsche Bank Group.

Department of Communications, Energy and Natural Resources (2006). Correspondence between the European Commission and Ireland on REFIT 1 state aid application [online]. Available: http://www.dcenr.gov.ie/Energy/Sustainable + and + Renewable + Energy + Division/REFIT.htm [Accessed: 12 February 2015].

Department of Communications, Energy and Natural Resources (2011). National Renewable Energy Action Plan Ireland. Submitted under Article 4 of Directive 2009/28/EC [online]. Available: http://www.dcenr.gov.ie/NR/rdonlyres/ C71495BBDB3C-4FE9-A725-0C094FE19BCA/0/2010NREAP.pdf [Accessed: 26 November 2014].

Department of Energy and Climate Change (2011). UK Renewable energy roadmap. Department of Energy \& Climate Change, London.

Department of Energy and Climate Change (2012). Feed-in Tariffs Scheme. Government response to Consultation on Comprehensive Review Phase 2A: Solar PV cost control. Department of Energy \& Climate Change, London.

Devitt, C. and L. Malaguzzi Valeri (2011). "The Effect of REFIT on Irish Wholesale Electricity Prices." The Economic and Social Review 42(3): 343-369.

Doherty, R. and M. O’Malley (2011). “The efficiency of Ireland's Renewable Energy Feed-In Tariff (REFIT) for wind generation.” Energy Policy 39(9): 4911-4919. http://dx.doi.org/10.1016/j.enpol.2011.06.024.

E.C. (2007). An energy policy for europe. Brussels: Office for Official Publications of the European Communities.

Farrell, N. and S. Lyons (2015). "Who should pay for renewable energy? Comparing the household impacts of different policy mechanisms in Ireland.” In press: Energy Research \& Social Science.

Fleten, S.-E., K. Maribu, and I. Wangensteen (2007). "Optimal investment strategies in decentralized renewable power generation under uncertainty.” Energy 32(5): 803 - 815. http://dx.doi.org/10.1016/j.energy.2006.04.015.

Folketinget Danish Parliament (2008). "Promotion of Renewable Energy Act." Act no. 1392 of 27 December 2008.

Fudenberg, D. and J. Tirole (1991). Game theory. Cambridge, Massachusetts: MIT Press.

Gallego-Castillo, C. and M. Victoria (2015). "Cost-free feed-in tariffs for renewable energy deployment in Spain." Renewable Energy 81: 411-420. http://dx.doi.org/10.1016/j.renene.2015.03.052.

Heydari, S., N. Ovenden, and A. Siddiqui (2012). "Real options analysis of investment in carbon capture and sequestration technology." Computational Management Science 9(1): 109-138. http://dx.doi.org/10.1007/s10287-010-0124-5.

Hull, J. C. (2003). Options, Futures, and Other Derivatives. London: Pearson Prentice-Hall.

IEA and OECD (2008). Deploying renewables principles for effective policies: in support of the G8 plan of action. Paris: OECD/IEA.

IWEA (2011). The impact of wind on pricing within the Single Electricity Market [online]. Available: http://www.iwea.com [Accessed: 12 February 2015].

Jacobs, D. (2014). "Policy invention as evolutionary tinkering and codification: the emergence of feed-in tariffs for renewable electricity." Environmental Politics 23(5): 755-773. http://dx.doi.org/10.1080/09644016.2014.923627.

Copyright (C) 2017 by the IAEE. All rights reserved. 
Kalkuhl, M., O. Edenhofer, and K. Lessmann (2012). "Learning or lock-in: Optimal technology policies to support mitigation." Resource and Energy Economics 34(1): 1-23. http://dx.doi.org/10.1016/j.reseneeco.2011.08.001.

Keppo, J. and M. Rasanen (1999). "Pricing of electricity tariffs in competitive markets." Energy Economics 21(3): 213223. http://dx.doi.org/10.1016/S0140-9883(99)00005-5.

Kim, K.-K. and C.-G. Lee (2012). "Evaluation and optimization of feed-in tariffs.” Energy Policy 49: 192-203. http:// dx.doi.org/10.1016/j.enpol.2012.05.070.

Kitzing, L. (2014). "Risk implications of renewable support instruments: Comparative analysis of feed-in tariffs and premiums using a mean-variance approach.” Energy 64: 495-505. cited By 0. http://dx.doi.org/10.1016/j.energy.2013.10.008.

Kopsakangas-Savolainen, M. and R. Svento (2013). "Promotion of Market Access for Renewable Energy in the Nordic Power Markets.” Environmental and Resource Economics 54(4): 549-569. http://dx.doi.org/10.1007/s10640-012-9605Z.

Krozer, Y. (2013). "Cost and benefit of renewable energy in the European Union.” Renewable Energy 50: 68-73. http:// dx.doi.org/10.1016/j.renene.2012.06.014.

Lyle, M. R. and R. J. Elliott (2009). “A 'simple' hybrid model for power derivatives.” Energy Economics 31: 757-767. http://dx.doi.org/10.1016/j.eneco.2009.05.007.

McGarrigle, E., J. Deane, and P. Leahy (2013). "How much wind energy will be curtailed on the 2020 Irish power system?" Renewable Energy 55: 544-553. http://dx.doi.org/10.1016/j.renene.2013.01.013.

Neuhoff, K., S. Bach, J. Diekmann, M. Beznoska, and T. El-Laboudy (2013). "Distributional Effects of Energy Transition: Impacts of Renewable Electricity Support in Germany." Economics of Energy \& Environmental Policy 2(1). http:// dx.doi.org/10.5547/2160-5890.2.1.3.

Overdahl, J. A. and H. L. Matthews (1988). "The Use of NYMEX Options to Forecast Crude Oil Prices." The Energy Journal 9(4): 135-147. http://dx.doi.org/10.5547/ISSN0195-6574-EJ-Vol9-No4-7.

Pickles, E. and J. L. Smith (1993). "Petroleum Property Valuation: A Binomial Lattice Implementation of Option Pricing Theory.” The Energy Journal 14(2): 1-26. http://dx.doi.org/10.5547/ISSN0195-6574-EJ-Vol14-No2-1.

Pindyck, R. (1999). “The long-run evolution of energy prices.” The Energy Journal 20(2): 1-27. http://dx.doi.org/10.5547/ ISSN0195-6574-EJ-Vol20-No2-1.

Pinkdyck, R. S. (2001). “The Dynamics of Commodity Spot and Futures Markets: A Primer.” The Energy Journal 22(3): 1. http://dx.doi.org/10.5547/ISSN0195-6574-EJ-Vol22-No3-1.

Queensland Competition Authority (2013). Estimating a Fair and Reasonable Solar Feed-in Tariff for Queensland [online]. http://www.qca.org.au/files/ER-QCA-FinalReport-ReviewofSolarFeedinTariffQLD-0313.pdf [Accessed: 24 August 2013].

Ragwitz, M., A. Held, G. Resch, T. Faber, R. Haas, C. Huber, R. Coenraads, M. Voogt, G. Reece, P. Morthorst, S. Jensen, I. Konstantinaviciute, and B. Heyder (2007). Assessment and Optimization of Renewable Energy Support Schemes in the European Electricity Market: Final Report. Karlsruhe, Germany: Optimization of Renewable Energy Support (OPTRES) project for the European Commission, DG TREN, and Intelligent Energy for Europe (IEE).

Rigter, J. and G. Vidican (2010). "Cost and optimal feed-in tariff for small scale photovoltaic systems in China." Energy Policy 38(11): 6989-7000. http://dx.doi.org/10.1016/j.enpol.2010.07.014.

Schwartz, E. and J. E. Smith (2000). "Short-Term Variations and Long-Term Dynamics in Commodity Prices." Management Science 46: 893-911. http://dx.doi.org/10.1287/mnsc.46.7.893.12034.

SEAI (2011). SEAI Wind Energy Roadmap 2011-2050. Report of the SEAI Energy Modelling Group.

SEMO (2011). SEM Data Publication Reports [online]. http://www.sem-o.com/marketdata/Pages/default.aspx [Accessed: 14 July 2013].

Sensfuß, F., M. Ragwitz, and M. Genoese (2008). "The merit-order effect: A detailed analysis of the price effect of renewable electricity generation on spot market prices in Germany." Energy Policy 36(8): 3086-3094. http://dx.doi.org/10.1016/ j.enpol.2008.03.035.

Shreve, S. E., P. Chalasani, and S. Jha (2004). Stochastic calculus for finance, Volume 1. Springer New York.

Siddiqui, A. and S.-E. Fleten (2010). "How to proceed with competing alternative energy technologies: A real options analysis." Energy Economics 32(4): 817-830. http://dx.doi.org/10.1016/j.eneco.2009.12.007.

Siddiqui, A. S. and K. Maribu (2009). "Investment and upgrade in distributed generation under uncertainty." Energy Economics 31(1): 25-37. http://dx.doi.org/10.1016/j.eneco.2008.08.007.

Skantze, P., M. Ilic, and J. Chapman (2000). "Stochastic modeling of electric power prices in a multi-market environment." In Power Engineering Society Winter Meeting, 2000. IEEE, Volume 2, pp. 1109-1114. http://dx.doi.org/10.1109/ PESW.2000.850096.

Smith, J. L. (2005). "Petroleum Prospect Valuation: The Option to Drill Again.” The Energy Journal 26(4): 53-68. http:// dx.doi.org/10.5547/ISSN0195-6574-EJ-Vol26-No4-4.

Copyright (C) 2017 by the IAEE. All rights reserved. 
Tsitakis, D., S. Xanthopoulos, and A. Yannacopoulos (2006). "A closed-from solution for the price of cross-commodity electricty derivatives.” Physica A 371: 543-511. http://dx.doi.org/10.1016/j.physa.2006.03.037.

Wickart, M. and R. Madlener (2007). "Optimal technology choice and investment timing: A stochastic model of industrial cogeneration vs. heat-only production." Energy Economics 29(4): 934-952. http://dx.doi.org/10.1016/ j.eneco.2006.12.003.

Woo, C.-K. (1988). "Optimal electricity rates and consumption externality.” Resources and Energy 10(4): 277-292. http:// dx.doi.org/10.1016/0165-0572(88)90007-2.

Yang, M. and W. Blyth (2007). Modeling investment risks and uncertainties with real options approach. A Working Paper for an IEA Book: Climate Policy Uncertainty and Investment Risk.

Zhu, L. (2012). “A simulation based real options approach for the investment evaluation of nuclear power." Computers \& Industrial Engineering 63(3): 585-593. 


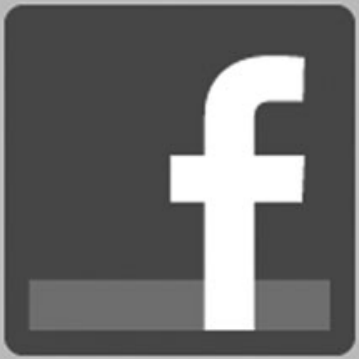

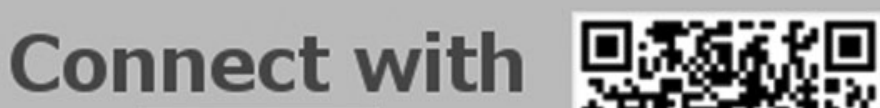

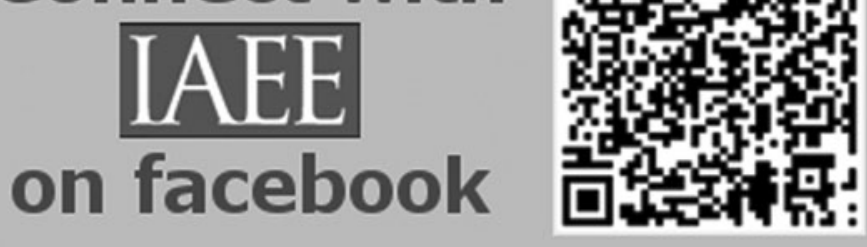

